\title{
O TRABALHO DE GRUPO: REFLEXÕES DO COTIDIANO, RELATO DE UMA EXPERIÊNCIA*
}

\author{
Sônia Camila Sant'Anna** \\ Maria das Graças Carvalho Ferriani***
}

SANT'ANNA, S.C.; FERRIANI, M. das G.C. O trabalho de grupo: reflexões do cotidiano, relato de uma experiência. Rev.latino-am.enfermagem, Ribeirão Preto, v. 8, n. 3, p. 97-101, julho 2000.

O objetivo deste trabalho consistiu no resgate do assistir em grupo numa unidade básica de saúde, oferecendo ações de enfermagem desvinculadas das ações médicas. Como referencial teórico utilizamos ALMEIDA \& ROCHA (1997); CAMPOS (1992) e MERHY (1995). Para os grupos nos embasamos em MUNARI \& RODRIGUES (1997) e LOPES \& MANZOLI (1996). De agosto de 1995 a dezembro de 1997 atendemos 108 clientes que espontaneamente buscavam orientação alimentar para perda de peso. Todos os participantes afirmaram mudanças significativas em suas vidas, $85 \%$ tiveram perda de peso e o grupo hoje é reconhecido pela clientela e pela equipe de saúde.

UNITERMOS: educação em saúde, educação em enfermagem, prática de grupo

\section{INTRODUÇÃO}

A crise do setor saúde no final dos anos 70 levantou um amplo debate desencadeando processo da Reforma Sanitária, o qual propõe a reestruturação desse setor tendo como estratégia a conformação do Sistema Único de Saúde (SUS) legalizado com a Constituição de 88 (BRASIL,1988), assim novas diretrizes e formas de organização da assistência se fizeram necessárias.

Ao final dos anos 80 como reflexo desse processo a forma de atuação dos profissionais na área da saúde pública sofre transformações. ALMEIDA (1991) analisando o trabalho de enfermagem na rede básica de saúde de Ribeirão Preto, identificou o modelo de assistência do pronto-atendimento que consistia na consulta e conduta centrada na queixa imediata referida pelos clientes.

Ainda o estudo de ALMEIDA (1991) apontou que as atividades de enfermagem estavam voltadas para as ações complementares da consulta médica, tais como: aplicação de tratamento e curativos, aerosóis.

Houve um esvaziamento dos grupos de orientação e atendimento de enfermagem, os profissionais alegavam que a clientela buscava apenas o atendimento médico realizado o mais rápido possível de modo a permanecer menor tempo na unidade de saúde.

A ineficácia deste modelo queixa-conduta foi logo percebida, como comenta ASSIS (1996) no seu estudo analisando o trabalho da enfermeira na rede básica, sugerindo retomar atividades de caraterísticas mais amplas, como os trabalhos de grupo.

Com vista a contribuir para mudança no atual modelo de assistência, na perspectiva da construção do Sistema Único de Saúde (SUS), apresentamos a experiência de uma unidade básica de saúde quanto ao resgate da prática de trabalho de grupo como estratégia de oferecer outras formas de atendimento a saúde além da consulta médica.

\section{REFERENCIAL TEÓRICO}

Este trabalho está baseado no referencial teórico do processo de trabalho em saúde utilizado por ALMEIDA \& ROCHA (1997), o qual percebe a enfermagem como uma prática social articulada à outras práticas. Fomos influenciadas também pelas idéias de CAMPOS (1992) e MERHY (1995), os quais propõem um novo agir em saúde, através da reorganização das ações oferecidas pelas equipes de saúde com a

\footnotetext{
* Trabalho apresentado do VI Colóquio de Investigação em Enfermagem, maio 1998

** Enfermeira do CSE de Ribeirão Preto da Universidade de São Paulo, doutoranda do Programa Interunidades da Escola de Enfermagem de Ribeirão Preto da Universidade de São Paulo

*** Orientadora. Professor Titular do Departamento de Enfermagem Materno-Infantil e Saúde Pública da Escola de Enfermagem de Ribeirão Preto da Universidade de São Paulo
} 
participação da clientela na decisão do que é oferecido, significando uma relação mais humanizada e próxima da necessidade referida pela clientela. Propõem ainda que as ações promovam nos clientes autonomia no caminhar da vida.

\section{METODOLOGIA}

Este trabalho se insere na linha da pesquisa qualitativa, trazendo uma descrição do processo de organização e sistematização da assistência em grupo, durante o mesmo o autor atuou como participante e observador. Como norteador desse caminho entre teoria e prática utilizamos os pressupostos de TRIVINÕS (1987) e MINAYO et al. (1998).

Os dados observados e divulgados tiveram o consentimento dos membros que participaram dos grupos e o trabalho teve parecer favorável da Comissão de Ética do Centro de Saúde Escola.

Esse processo envolveu outros profissionais do serviço, além de outra enfermeira, também, atuaram uma psicóloga e uma farmacêutica.

\section{O CENÁRIO DO ESTUDO}

Este trabalho foi desenvolvido na Unidade Básica do Sumarezinho do Centro de Saúde Escola (CSE), serviço de extensão universitária criado em 01 de março de 1979 através do convênio entre a Secretaria de Estado da Saúde de São Paulo e a Universidade de São Paulo (USP). Gerenciado pelo Departamento de Medicina Social da FMRP-USP desde sua criação até 1997 conta com as Unidades Básicas de Saúde do Ipiranga e de Vila Tibério e da Unidade Básica e Distrital do Sumarezinho, sendo esta referência para nove Unidades Básicas.

A unidade escolhida tem como objetivo o ensino, a pesquisa e a assistência primária à saúde da criança, da mulher, do adulto e do idoso para uma população estimada de 60.000 habitantes e assistência secundária nas áreas de Pediatria, Ginecologia-Obstetrícia, Cardiologia, Saúde Mental, Oftalmologia, Dermatologia, Moléstias InfectoContagiosas, Saúde do Trabalhador, para uma população estimada de 125.000 habitantes.

A partir de 1993 foram introduzidas no CSE práticas de emergências, além das atividades de vigilância em saúde e das práticas da assistência programática. Articulado ao processo de municipalização da saúde passaram a integrar o quadro de pessoal, além dos contratados pela USP e pela Secretaria de Estado da Saúde de São Paulo, os servidores da Secretaria Municipal da Saúde em regime de plantão respondendo pelo atendimento de 24 horas.

Como reflexo de novo ordenamento administrativo, o modelo de assistência também se alterou, deixaram de realizar atividades de enfermagem como: grupo de enfermagem, atendimento de enfermagem e visitas domiciliares.

Os motivos alegados eram o reduzido quadro de pessoal e a crescente demanda por ações complementares à consulta médica, sendo que uma única consulta gerava outras ações, a saber: antropometria, verificação dos sinais vitais, aerosóis, curativos, injeções e orientação para exames solicitados, também atribuíam um desinteresse da clientela por trabalhos de grupo.

Nosso pressuposto era que a clientela utilizava a assistência disponível nos serviços de saúde, os profissionais executavam ações segundo seu entendimento, não a partir de decisões compartilhadas com as necessidades e solicitações dos usuários.

\section{O TRABALHO DE GRUPO E A ENFERMAGEM}

A utilização da estratégia de grupo para assistir pessoas por parte dos enfermeiros remonta à década de setenta, tendo a saúde pública como pioneira com grupos de orientação à gestante.

Ao final dos anos 70 a enfermagem já atendia em grupo uma clientela variada: problemas de locomoção, hanseníase, de obesidade, de cardiopatias, de mães, de adolescente, de diabéticos entre outros (MUNARI \& RODRIGUES,1997).

Autores como LOPES \& MANZOLI (1996) e MUNARI \& RODRIGUES (1997) estudaram as características de assistir em grupo usadas na enfermagem de modo geral e na enfermagem psiquiátríca em particular. Afirmam que grupo é um espaço de construção conjunta da realidade baseada na solidariedade.

Concordamos com as autoras e com esta premissa construímos um espaço de ações/decisões conjuntas entre profissionais/clientes, isto significou implementar uma atividade requerida pela clientela.

\section{A OBESIDADE COMO PROBLEMA}

A obesidade e a desnutrição são na atualidade problemas de relevância epidemiológica, sendo que a obesidade pode estar associada a doenças como as cardiovasculares e seus fatores de risco como hipertensão e hiperlipidemias, ao "diabetes mellitus", decorrente de dietas inadequadas. Tal situação ocorre tanto em países ricos ou pobres, estão ambos apresentando altas taxas de 
obesidade (MONDINI \& MONTEIRO,1998).

A vigilância nutricional da criança, do adolescente a do adulto é objeto de estudo de vários autores como VARGAS \& SCAIN (1983); ANJOS et al. (1992); MONDINI \& MONTEIRO (1998), os quais discutem amplamente os fatores determinantes da desnutrição e da obesidade, e apontam a educação como uma das formas de solução do problema.

Vale destacar dentre os estudos citados a prevalência de obesidade em adolescente e adulto é de 20 a $25 \%$, tanto em homens quanto em mulheres, em todas as classes sociais.

Em levantamento bibliográfico na base de dados LILACS, para os anos de 80 até 97, sobre grupo de orientação para perda de peso na enfermagem encontramos o trabalho de (VARGAS \& SCAIN ,1983).

Apesar das estatísticas e de ser considerada fator de risco, a idéia de organizar um grupo de orientação para obesos partiu da necessidade da clientela. Desta forma, no segundo semestre de 1995, assumimos uma demanda espontânea de 30 mulheres que buscavam orientação alimentar para perda de peso.

\section{DESENVOLVIMENTO DO TRABALHO}

Da clientela que procurava a Unidade Básica do Sumarezinho, estruturamos um Grupo de Orientação para o Controle de Peso.

Estabelecemos para cada grupo um total de 14 reuniões, uma vez por semana, com duração máxima de duas horas; no primeiro encontro fixávamos o contrato quanto aos 14 encontros e os participantes expunham suas expectativas e metas.

Em cada reunião era abordado um tema principal e uma orientação alimentar a partir de cardápios básicos para reeducação alimentar.

Os assuntos abordados em cada reunião, eram elencados a partir das necessidades verbalizadas pelos membros do grupo e à coordenadora cabia a tarefa de facilitar as discussões e a participação.

Os temas foram trabalhados utilizando-se técnicas e dinâmicas de grupos, adaptando à realidade o material do INSTITUTO da PASTORAL da JUVENTUDE (1997) e Oficina de Dinâmica de Grupos de (MIRANDA, 1996). As seguintes questões emergiram como tema para discussão nas reuniões grupos:

Porque sou gorda?

Por que estou aqui?

Quando o excesso de peso começou a incomodar?

Remédio para emagrecer:sim/não, por que?

Como me comporto diante dos alimentos?

Qual o espaço na minha vida para: a atividade física, o lazer e o trabalho?
Como me relaciono com minha família? Eu e/ou com outros?

Quais foram/serão meus planos/metas?

A perda de peso como meta?

A cada reunião na primeira hora era relizada a orientação alimentar, seguindo como referência BURTON (1979) e MOTTA \& BOOG (1984). E ainda, na segunda hora do encontro, o tema da discussão era introduzido a partir de técnicas de dinâmicas de grupo; ao final promovíamos uma avaliação do conteúdo da discussão e era proposto o tema da reunião seguinte.

A dinâmica da $1^{\mathrm{a}}$ até a $14^{\mathrm{a}}$ reunião terminava com uma síntese preparando os participantes a caminharem sozinhos, sabendo que poderiam voltar a compor um novo grupo conforme desejassem.

\section{RESULTADOS E DISCUSSÃO}

No primeiro grupo organizado, composto somente por mulheres, não fixamos o número de membros, contudo com a divulgação do trabalho, passamos a ter maior procura, para melhor atender a demanda começamos a elaborar lista de espera e limitar cada grupo a trinta participantes no máximo.

De agosto de 1995 à dezembro de 1997 realizamos cinco grupos atendendo um total de 108 clientes, na faixa etária de 13 a 70 anos.

Neste período apenas dois homens procuraram o grupo, um adolescente de 13 anos por iniciativa da mãe e um homem de 45 anos por orientação do clínico da unidade. Ambos compareceram em apenas três encontros, não retornando mesmo após serem contactados pela coordenação. Outros estudos poderão explorar a adesão masculina a trabalhos de grupos.

Entendemos como sucesso não apenas a perda de peso, mas como cada membro se colocava ao final das 14 reuniões. Tivemos $5 \%$ de abandono, isto é, pessoas que freqüentaram uma ou duas reuniões e não retornaram, mesmo após contactadas pela coordenadora.

Como dados mais objetivos, no tocante a perda de peso, $85 \%$ dos participantes tiveram sucesso. Quanto as alterações metabólicas, $10 \%$ dos participantes relataram diminuição nos níveis séricos de colesterol e taxa de glicemia, $2 \%$ tiveram suspensão da medicação oral para hipertensão e diabetes.

No aspecto qualitativo, todos os participantes afirmaram que compartilhar do grupo trouxe significativas mudanças para suas vidas, no aspecto da auto-estima, segurança e melhora da convivência com a família.

O trabalho de grupo é uma possibilidade de atendimento de enfermagem sistematizado e incorporado 
na rotina da Unidade Básica do Sumarezinho, há procura espontânea por parte da clientela.

Percebemos ainda que algumas áreas de especialidade médica programática, tais como clínica geral, psiquiatria e saúde da mulher encaminharam clientes reconhecendo a necessária complementariedade dos saberes.

Esta experiência demonstrou que a clientela quando assistida no seu carecimento, responde a quem a acolheu participando e divulgando a outros, tornam-se também educadores e independentes, esperamos com este relato estimular outros profissionais e serviços a organizarem ações contemplando o olhar do cliente.
Temos clareza das limitações impostas ao presente trabalho, não tivemos a pretensão de esgotar o assunto, mas expor uma experiência em defesa dessa forma de atuação para a equipe de enfermagem.

Para concluir retomamos o relato de MUNARI \& RODRIGUES (1997):

"entender um grupo como um espaço de troca de experiência é vê-lo servir como agente de transformação, quanto mais existirem atitudes de acolhimento e de solidariedade entre seus membros, maiores as chances do desenvolvimento de potencialidades individuais e coletivas...um grupo é aquilo que seus membros fazem dele".

\section{GROUP ACTIVITES: DAY BY DAY CONSIDERATIONS, AN EXPERIENCE REPORT}

The purpose of the present study was to analyze the meaning of the care delivered by a group of professionals at a basic health unit, in order to propose nursing actions that are not linked to medical actions. As theoretical references, authors used ALMEIDA \& ROCHA(1997) and the ideas of CAMPOS (1992) and MERHY(1995). Regarding the group activities, authors used MUNARI \& RODRIGUES(1997) and LOPES \& MANZOLI(1996) considerations. From August 1995 to December 1997, authors attended 108 clients that spontaneously asked for nursing orientation in order to loose weight. All those showed significant changes in theirs lives and $85 \%$ lost weight. Nowadays, the group is recognized by the clientele and by the health team.

KEY WORDS: health education, nursing education, group practice

\section{EL TRABAJO DE GRUPO: REFLEXIONES DEL COTIDIANO, RELATO DE UNA EXPERIENCIA}

Este trabajo consistió en la sistematización de la asistencia en grupo realizado en una unidad básica de servicios, ofreciendo acciones de enfermería separadas de las acciones médicas. Como referencial teórico utilizamos a ALMEIDA \& ROCHA(1997) y los principios de CAMPOS(1992) y MERHY(1995). Para organizar los grupos nos basamos en MUNARI \& RODRIGUES(1997) y LOPES \& MANZOLI(1996). A partir de la demanda que buscaba orientación para conseguir la pérdida de peso. Estructuramos los grupos, atendimos a 108 clientes, $85 \%$ tuvieron pérdida de peso y $5 \%$ abandono, esta actividad hoy es reconocida por la clientela, como forma de asistencia, además del reconocimiento de otros miembros del equipo de salud. Esperamos con este relato estimular otros profesionales y servicios.

TÉRMINOS CLAVES: educación en salud, educación en enfermería, práctica de enfermería

\section{REFERÊNCIAS BIBLIOGRÁFICAS}

01. ALMEIDA, M.C.P. O trabalho de enfermagem e sua articulação como processo de trabalho em saúde coletiva: rede básica de saúde. Ribeirão Preto, 1991. Tese (Livre-Docência) - Escola de Enfermagem de Ribeirão Preto, Universidade de São Paulo.

02. ALMEIDA, M.C.P.; ROCHA, S.M.M. (orgs). O trabalho de enfermagem. São Paulo: Cortez, 1997.

03. ANJOS, L.A.; SILVA, D.O.; SERRAO, S.A.; SILVA, C.V.C. Vigilância nutricional em adultos: experiência de uma unidade de saúde atendendo população favelada. Cad.Saude Pública, v. 8, n. 1, p. 50-56, jan/mar. 1992.
04. ASSIS, M.M.A. O fazer da enfermeira no sistema local da saúde: individual ou coletivo? Rev.Bras. Enfermagem, Brasília, v. 49, n. 3, p. 363-372, jul/set. 1996.

05. BRASIL. Constituição (1988). Constituição da República Federativa do Brasil. Brasília: Centro Gráfico do Senado Federal, 1988.

06. BURTON, B. Nutrição humana. São Paulo: Mcgraw-Hill, 1979.

07. CAMpos, G.W. A reforma da reforma. Repensando a Saúde. São Paulo: HUCITEC, 1992. 
08. INSTITUTO da PASTORAL da JUVENTUDE Leste II. São Paulo. Recriando experiências, técnicas e dinâmicas para grupos. São Paulo:Paulus, 1997.

09. LOPES, M.E.E.F.; MANZOLI, M.C. Grupalidade em enfermagem psiquiátrica: algumas questões. In: MANZOLI, M.C. (org). Enfermagem psiquiátrica da enfermagem psiquiátrica à saúde mental. Rio de Janeiro: Guanabara/ Koogan, 1996.

10. MERHY, E.E. Por um modelo técnico-assistencial da política de saúde em defesa da vida:contribuições para conferências em saúde. Saúde em Debate, n. 33, p. 83-89, 1995.

11. MINAYO, M.C. (org). et al. Pesquisa social: teoria, método e criatividade. 8. ed. Petrópolis: Vozes, 1998.
12. MIRANDA, S. Oficina de dinâmica de grupos para empresas, escolas e grupos comunitários. Campinas: Papirus, 1996.

13. MONDINI, L.; MONTEIRO, C.A. Relevância epidemiológica da desnutrição e da obesidade em distintas classes sociais:métodos de estudo e aplicação à população brasileira. Rev. Bras.Epidemiol., v. 1, n. 1, p. 28-39, abr. 1998.

14. MOTTA, D.G.; BOOG, M.C.F. Educação nutricional. São Paulo: IBRASA, 1984.

15. MUNARI, D.B.; RODRIGUES, A.R.F. Enfermagem e grupos. Goiania: A B, 1997.

16. TRIVIÑOS, A.N. Introdução à pesquisa em ciências sociais: a pesquisa qualitativa em educação. São Paulo: Atlas, 1987.

17. VARGAS, G.O.; SCAIN, S.F. Educação para saúde a grupos de obesos. Rev.Bras.Enfermagem, v. 36, n. 1, p. 38-49, jan/mar. 1983. 